\title{
Looking back on looking forward: Re-introducing Merv Hancock's article ten years on
}

Kate van Heugten

Kate van Heugten, former Book Review Editor for Social Work Review. Head of School, School of Social Work and Human Services, University of Canterbury.

Hancock, M. (1998). The social work profession: Now and in the next ten years. Social Work Review, 10(4), pp.2-5.

I felt privileged, but admittedly also rather daunted, by the task of reviewing 10 years of articles published between 1994 and 2004 in order to make a selection for a commemorative issue. I did the sums: seven articles times four issues per year times 10 years equals at least 280 options. My pile of possible contenders grew, replete with famous and well respected names coupled with pivotal content.

And then it happened: All of these qualities coincided in one sterling paper, with an added bonus. Precisely 10 years ago, in December 1998, Merv Hancock supplied the perfect title to invite our reconsideration: The social work profession: Now and in the next 10 years. Merv wrote about the professional project on which we were consciously and unconsciously embarked, and about where it might take us. He laid out aspects of our economic, social and ethical objectives, and touched on the bicultural issues that needed to be tackled more actively.

The unifying and seemingly single collective he appeared to task with significant responsibility for improving our income and status, was the Aotearoa New Zealand Association of Social Workers. That was fitting at the time of writing, when the current government was adopting a deregulatory stance toward professions, and employers and managers were frequently at odds with social workers about such issues as efficient and cost effective versus quality service, and control over work more generally. These struggles arose at least in part as a consequence of a recession. But as Merv also pointed out '... the State may also fluctuate in its views with contradictory positions adopted within a single five year period and changed in another' (p. 5). As indeed they did with the passing of the Social Workers Registration Act 2003. Doubtless the passing of this act has created new 'bump chains', as Abbott (1988) would call them, in contests over control of work and the right to set and patrol professional boundaries. Have battles over control of work between managers and workers abated, or will these quickly resurface following the onset of the recession of 2008-? I leave it to the reader to ponder these and other matters as you visit or revisit this important article by our life member. I present to you, a gentle man and wonderful thinker I am proud to know, our Merv Hancock. 